feelings and attitudes to mental handicap, diagnosis of mental illness in people with mental handicap, confronting ethical issues, secondary handicaps, life events, causes of and management of behaviour disorders, child development, multidisciplinary team work, family dynamics and informing the family of the handicap).

When questioned about their attachment to the psychiatry of mental handicap, most students had enjoyed it and found it useful. However, a significant minority (18\%) still felt they did not understand the needs of people with a mental handicap and required increased skills in interacting with them, and also more knowledge of community services.

\section{Comments}

The confusion that existed for some students after the course between the terms mental handicap and mental illness is a cause for concern. This confusion has been reported before in a separate group of students (Holt \& Bouras, 1988). Careful consideration of how to overcome this should be given. It may reflect a situation where teaching about the psychiatric needs of people with a mental handicap occurs in a separate course unit to the other medical needs of this population, so that the terms mental handicap and psychiatry become fused for some students. A more integrated approach to student teaching is now being developed with contributions from other professionals (speech therapists, occupational therapists, physiotherapists, psychologists, nurses).

The majority of students had had contact with a person with mental handicap by the end of their psychiatry placement. The observation that the students rated people with a mental handicap whom they had met as more likely to be violent or physically disabled after the course than before probably reflects the more disabled population who use specialist services, rather than reflecting a more general shift in the students' attitudes. This may also contribute to the students' confusion between the terms mental handicap and mental illness.

Some ratings demonstrated that students still felt quite uncomfortable being around people with a mental handicap, even after the course. Yet as a group they remained interested in the topic and were eager to learn about some of the challenging areas such as ethical issues, and informing parents of their child's handicap. The course at this time was short and did not include discussion groups, although there were opportunities for a dialogue at the end of each lecture and during the day with the Service. It may be that students would benefit from role play and discussion of their feelings in a group (Hollins, 1988); such sessions might also facilitate a clarification of concepts. As doctors in all fields of medicine are increasingly being asked to see people with a mental handicap, it is important that the training they receive equips them to feel confident and competent to meet these people's needs.

\section{Acknowledgement}

We are grateful to $\mathrm{Dr} C$. Drummond for her contribution in executing this study.

\section{References}

Holuins, S. (1988) How mental handicap is taught in UK medical schools. Medical Teacher, 10, 289-295.

Holt, G. \& Bouras, N. (1988) Attitudes of medical students to mental handicap. Medical Teacher, 10, 305-307.

\title{
Audit workshops
}

Tackling audit: a series of one-day workshops for occupational therapists, psychiatrists, clinical psychologists, CPNs and psychiatric nurses will be held in February and March 1993. Further information: Andrea L. Jackson, The Nuffield Institute for Health
Services Studies, NHS and Social Care Division, 71-75 Clarendon Road, Leeds LS2 9PL (telephone 0532 459034, quote reference number HG124; fax 0532 460899). 